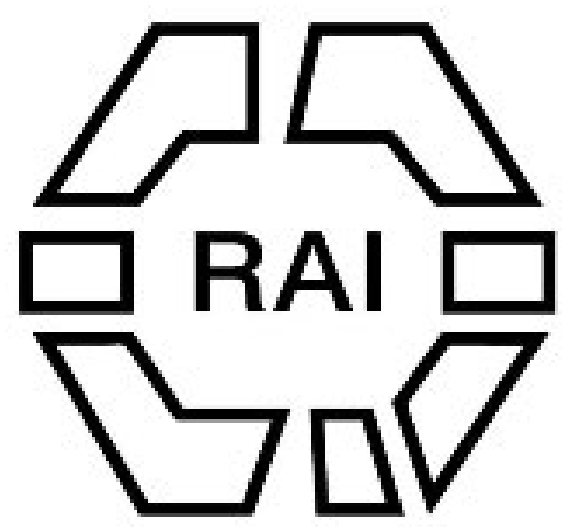

The Manufacture of Pottery in Upper Egypt

Author(s): D. Randall-MacIver

Source: The Journal of the Anthropological Institute of Great Britain and Ireland, Vol. 35

(Jan. - Jun., 1905), pp. 20-29

Published by: Royal Anthropological Institute of Great Britain and Ireland

Stable URL: http://www.jstor.org/stable/2843113

Accessed: 10/06/2014 23:21

Your use of the JSTOR archive indicates your acceptance of the Terms \& Conditions of Use, available at http://www.jstor.org/page/info/about/policies/terms.jsp

JSTOR is a not-for-profit service that helps scholars, researchers, and students discover, use, and build upon a wide range of content in a trusted digital archive. We use information technology and tools to increase productivity and facilitate new forms of scholarship. For more information about JSTOR, please contact support@jstor.org.

Royal Anthropological Institute of Great Britain and Ireland is collaborating with JSTOR to digitize, preserve and extend access to The Journal of the Anthropological Institute of Great Britain and Ireland. 


\title{
THE MANUFACTURE OF POTTERY IN UPPER EGYPT.
}

\author{
By D. Randall-MacIver, M.A. \\ (Laycock Student of Egyptology at Worcester College, Oxford.)
}

[With Plates I-VI.]

THE principal pottery fabrics of Upper Egypt at the present day may be classified under three headings, viz. :-

I. Hoematitic wares, that is to say those in which the earthenware body is coated with a wash or slip of red hæmatite.

II. Painted wares, decorated with patterns upon a field formed by a slip of lighter colour which is not hæmatitic in composition.

III. Household pottery, which is seldom covered with any kind of slip.

To some extent this classification corresponds with a geographical distribution, inasmuch as the hæmatitic wares have evidently originated in Nubia, while the area in which painted pottery is made is confined to two or three places between Assuân and Keneh, and the non-hæmatitic household pottery, though manufactured everywhere north of Assuân, is foreign to Nubia.

I. In its original home the hæmatitic pottery is not ornamented except in so far as the few simple lines sometimes incised about the neck of a vessel (Plate I, Fig. 1) may be considered to constitute ornamentation. As found in Nubia, it is a plain hand-made fabric, of which the sole beauty is in the colour and burnish, for the varieties of form are very few. But at Assuân, and still more at Assiut, inventive potters have improved greatly upon the simple Nubian technique, and have produced a very delicate turned or moulded ware, characterised by an elaborate scheme of ornamentation, which is chiselled or stamped in low relief upon the polished surface of the hæmatitic slip.

The chief seat of the Nubian pottery manufacture is Umm-Barakat, a large village some 30 miles south of Assuân. The potters, who are all women, live in a few mud houses on the east bank, though the greater part of the village lies on the west bank of the Nile. The large red bowls and globular red pots (Plate I, Figs. 1 and 2) which are used in every household between Assuân and Wady Halfa are mostly made at this place, though the women of Umm-Barakat do not enjoy a complete monopoly, as there are potters who live in other villages further south, such as Kubbân, where, however, they only carry on their work in the summer months, so that the ordinary visitor has no opportunity of observing it. A single family has migrated from Umm-Barakat to Shammah, a few miles north of Assuân, and there (Plate II, Fig. 1) continues the industry, which is in danger of disappearing 
from the parent village in consequence of the desolation which the Assuân dam has wrought by flooding the fields from which the peasants obtained their scanty living.

At Shammah the entire family of potters was busily engaged when I arrived. The group of women may be seen in Plate II, Fig. 1, seated in an open space outside the houses and surrounded by their gossiping friends. On the left of the picture one is pounding broken potsherds upon a slab for the powder which must be mixed with the Nile mud to give it the requisite stiffness for making earthenware. In the centre two others are deftly shaping the pots, and some of the products of their skill may be seen in front of them. Their simple apparatus was spread out upon a small strip of grass-matting, and, besides the bowls filled with ashes upon which the clay is placed and worked freehand into shape, consisted only of (1) a bowl filled with the already kneaded clay, (2) a second bowl filled with water and (3) half a dozen of the large Nile shells which are used for smoothing the superfluous clay from the surface of the vessel as it is being made.

The process at Shammah was exactly the same as at Umm-Barakat (Plate II, Fig. 2) where a few days previously a wizened hag had consented to exhibit all the stages in the making of such specimens as are illustrated in Plate I, Figs. 1 and 2. The first thing to be done is to knead the clay. This, as has been already stated, is merely Nile mud mixed with a certain proportion of pounded fragments of old potsherds. A lump of the mud dough is placed upon a wide bowl filled with ashes which have been slightly damped. The lump is of such a size as will suffice for the making of the entire vessel, be it bowl or pot. For a bowl it will be a solid dise about 2 inches high, but for a globular pot it will be rolled into a ball rather than a disc. Taking a little water, the potter presses a hollow in the middle of the clay lump and begins to form it into shape, holding the outside of the growing vessel with her left hand and shaping it with her right. From time to time she twists the bowl of ashes from left to right in order to bring another part conveniently beneath her hand, and pulls the clay outwards from the middle of the lump to form the rapidly rising sides. With a little water she moistens the surface every now and then as it is required.

The rudimentary bowl will now be 2 or 3 inches in depth, its centre hollowed out but its sides still vertical and thick. The sides must next be heightened and thinned, to do which the potter takes a large shell of a common Nile variety and strokes the outer surface of the bowl upwards, producing at the same time the first indications of a curve in the section of the side. Then she shapes the interior still more with the right hand, and smooths the top surface to make the rim. Lastly, she smooths the interior ulso with the shell, and at the same time imparts to the sides the full convexo-concavity of a finished bowl (Plate I, Fig. 1).

A pot of globular form, such as that which is figured in Plate I, Fig. 1, is made in the same way. When it has been hollowed out in the centre, and its sides, vertical as yet, are 4 or 5 inches high, the potter takes the shell in her right hand, 
places her left against the inside, and so smoothing with the shell raises and thins the sides until she has produced a plain jam pot from 5 or 6 inches high. Then, holding her left hand against the outside and fashioning the interior with her right, she rapidly imparts the desired convexo-eoncavity and transforms the vertical walls of the jam pot into the rounded sides of a globular vessel. At this stage there is a slight variation from the former procedure, for, whereas the bowl was completed without the addition of any more clay to the original lump, in this case a little more clay must be taken from the reserve which stands near in order to finish off the rim of the pot. Then the outside is smoothed with the shell and the final degree of sphericity is given to the outline. One more stage, however, still remains before the formation of the globular pot is quite complete, and that is the adding of the foot or base-ring, which cannot be done for two or three days, when the vessel has been dried.

Though they have now received their permanent shape and outline, the bowl and the pot are not finished. Several more stages must intervene before they can be utilised for the purposes for which they are intended. First, they must be left to dry, which requires ten days in the open air. Next they must be coated with a substance which will render the porous clay impervious to liquids. For this purpose the Nubian potters use hæmatite which is found in the hills at no great distance. They pound it on a slab with a round stone until it is reduced to powder, then mix it with water and a little olive oil, and apply it to the surface of the pot with the hand (Plate II, Fig. 2). This would be sufficient for the mere utilitarian purpose of counteracting the porosity of the clay, but the potter is more ambitious, and is aware of the beautiful effect which can be produced by burnishing. The hæmatitic coating is therefore carefully burnished with a smooth oval pebble until it has acquired a glossy surface which glitters in the light. Finally, if the vessel is to be permanent, the soft clay must be hardened in the fire, a process which also takes place in the open air. The pots are piled within a ring of stones about 3 feet in diameter, over which the fuel is heaped and left to burn itself out. After a short interval has been allowed for cooling, they are then removed, and are ready to be sold or to be exported to other villages.

So far as I have been able to observe, the making of pottery by freehand is confined to Nubia. Shammah, which is a settlement of emigrants from UmmBarakat, is the only place north of Assuân where so primitive a procedure is still followed; all the other potters whom I have seen at work in Upper Egypt employ the lathe, the wheel, or the mould. Again, it is only in Nubia that women are the potters, elsewhere in Egypt the master-potter is always a man, and if the women take any part in the work, their share is confined to the burnishing and decorating. Moreover, not only the process of freehand working, but the use of the hæmatitic coating is distinctly Nubian. It is true that the finest and best known of the hæmatitic wares is made at Assiut, but I have ascertained by inquiries at both places that the Assiut potters learned their art at Assuân, while there can be little doubt that the Assuân fabric in its turn is evolved from that of Umm-Barakat. 
The Nubian hæmatitic ware is all intended for actual service, and is indeed the only pottery which is in general use throughout that part of the country. Its varieties of form are therefore few and simple. The Assuân and Assiut potters, on the other hand, do not make any ware for ordinary dumestic purposes, but exhibit their inventiveness in producing various fancy articles of an ornamental kind, such as coffee sets and vases, figures of camels, dogs, and crocodiles, candlesticks, censers, and pipes. Their command of more advanced technical appliances and of a superior quality of clay enables them to manufacture a pottery which is much esteemed for its beauty, and is sold in quantities to tourists and visitors. A link between the hand-made Nubian ware and the ornamental product of Assuân and Assiut is found at the village of Ballas, where, in addition to other classes of pottery which will presently be described, they make hæmatitic bowls resembling those of Shammah and Umm-Barakat in general appearance, but differing from them in the essential point that they are formed upon the wheel. That the manufacture is not native to Ballas may be inferred from the fact that they send to Assuân for their hæmatite; the clay of these bowls is of superior quality, consisting of about two-thirds Nile mud blended with about one-third of a white earth obtained in the neighbourhood. ${ }^{1}$

The ornamental hæmatitic wares are illustrated by the drawings in Plate I, Figs. 3-13, which are taken from examples bought at Assuân. The village where the potters live is outside Assuân itself, about half a mile from the bazaars. There are three manufactories, which are all worked by a single family consisting of eight men. In that which I visited the work was being carried on by two men, of whom one, the master, appeared to do little but attend to the firing. The other, who was seated in a half-open vestibule of the house, was busy at the lathe. The material of his pottery was a clay formed by blending Nile inud in equal parts with a white earth which is obtained from Shammah, though it is not used by the Shammah potters. The clay, after it has been properly kneaded, is placed in a receptacle beside the potter, who then takes out a lump of such size as he judges to be appropriate for the object which he intends to make, and squeezes it in his fingers to a convenient form for the lathe. Perhaps it is a pipe-bowl that he wishes to produce, in which case the lump of clay will be in the form of a hollow hemisphere, or perhaps the purchaser has ordered a cigar holder, and then a more convenient form to begin work upon is a long cylindrical roll.

The lathe is of a common type. Two boards are set up vertically about 15 inches apart on a wooden base, and held together by two horizontal struts. From the tops of the boards two pieces of iron project horizontally inwards and form the pivots, on to which a thin rod some 10 inches long is slipped. This rod is rotated by a bow about 30 inches long, which the operator works with one hand, while with the other he shapes and graves the clay as it revolves. The meaningless lump on the lathe rapidly acquires an outline under the skilful

${ }^{1}$ Other bowls made at Ballas have the hæmatitic slip outside but a white slip inside ; and others again have the white slip both inside and out. 
direction of the potter, Regulating the revolutions of the rod with his bow, he makes it move now fast, now slow, to suit his wants, and all the while as it turns he removes superfluous clay, cuts, smooths and graves. For these purposes he uses a set of iron tools, of which ten form a complete outfit. Besides these he possesses, and will use at this stage if he requires them, a series of wooden stumps for impressing the worm thread of a screw on pieces which are to be fitted together into some such composite construction as a candlestick or censer. The simplest elements of the ornamentation, viz., the concentric lines, are incised while the clay is still on the lathe, for a touch of the chisel on the soft surface of the revolving object produces a circle of such exactness as the unaided hand cannot emulate. But the greater part of the ornamentation is reserved for a later stage, and before it can be done the hæmatitic slip must be applied. The hæmatite, which is bought ready ground in the neighbouring bazaar, has been mixed with water and stands in a vessel beside the potter, who takes the newly-formed pipe-bowl, cup, or whatever the object may be, from the lathe and daubs the red wash on with his fingers, then smooths the surface with an iron smoother.

It is now that the real decoration begins. The clay is still quite soft, for the preceding stages have followed one another without interruption or interval. The Assuân artist chases his patterns with an iron tool ; and works from memory alone. But at Assiut the deplorably scientific potter from whom I bought some examples of the best work that is produced in Egypt, possessed wooden stamps with which he impressed all the more complicated patterns. This same man, to whom no further reference will be made, had discarded the lathe, and used in place of it solid moulds of hard wood or of pottery, upon which he shaped the several parts.

When the newly-made pot has been decorated, it is not ready to go at once to the fire, for the water in the clay would be converted into steam and burst it. Such a calamity actually occurred at Assuân, where, wishing to see this stage in the evolution of such little double vases as are figured in Plate I, Fig. 12, I induced the potter to fire them one day earlier than he would otherwise have done. The result was that a few minutes after the fire had been lighted a series of reports was heard, and only one out of the group of eight ultimately survived its ordeal of three-quarters of an hour. The furnaces at Assuân (Plate III, 1,2) were much like those of Umm-Barakat and Shammah, viz., circular holes, which, however, in this case were enclosed by bricks instead of stones. The kind of fuel used varies according to the degree of heat which is required. For the hæmatitic wares of Assuân and Assiut are turned out in either of two colours, viz., red or black, the difference between which is solely due to the difference in the intensity of the heat during firing. To produce the red colouring the only fuel used is animal dung, but if the potter wishes to obtain a black surface he adds a little chopped straw to the dung. This gives a fiercer heat and turns the hæmatitic slip black instead of red. ${ }^{1}$

1 At Assiut a third variety of ware is made which is similar to the hæmatitic in all other respects, but is coated with a cream-coloured slip. 
One stage still remains. This ornamental pottery, unlike the hand-made, is not burnished until it has been fired. The surface of the pot after firing is still quite dull and lustreless; but while it is still hot the potter polishes it to a glossy brightness, using for the purpose a cloth and two burnishers, one of which is a composite made of beeswax and a red substance called gum-bahár, while the other is just such a common smooth pebble as is used by the women at Shammah and Umm-Barakat. The pebble is apparently used for the interior, and the delicate exterior surface is only touched with the special composite burnisher.

II. Painted Ware such as that which is illustrated in Plate V is made only at two or three places in the Keneh province. I found it being manufactured with the household pottery at Edfu, Tukh, and Ballas. The first and the last of these towns are important centres of pottery making, and contain manufactories in which as many as half a dozen persons are employed simultaneously. In Plate III, 3, is shown a general view of the potters' establishment at Edfu. On the right of the picture two men are preparing the material, which is Nile mud mixed with ashes, and sometimes with a little chopped straw. Behind them is the wheel, the construction of which may be better understood from the illustration in Plate IV, 3 . In the centre and on the left stand a number of large basins and other varieties of household pottery, which are drying in the sun previous to being fired; amongst them sits the master-potter, who is scraping off the superfluous clay from the outside of a basin which has just been made. Against a wall in the extreme lefthand corner (distinguished by their whiteness) stand basins and bowls which belong to the class of painted pottery illustrated in Plate V; and if the picture could be slightly extended to the left, it would further include the women who are at work burnishing and decorating similar specimens.

The earlier stages in the manufacture of the painted ware are identical with those of the household ware to be described in the next section, and demand no special notice here. It is sufficient to remark that the pottery is all turned upon such a wheel as that illustrated in Plate IV, 3, and that it is always a man who works the wheel. The interesting time in the history of these pots begins when they have been removed from the wheel and sufficiently dried in the sun. Then they are handed over to the women, and pass through three more stages before they are ready to be fired. The first of these is the application of the slip, a white earth which the Edfu people bring from the hills half a day's distance from their village, but which the inhabitants of Tukh and of Ballas can find in the immediate neighbourhood of their homes. A thin wash made from this earth is daubed with a rag over the inside and outside of the bowl or plate, which is then laid on one side for a few minutes to dry. Next the slip surface is burnished with a smooth pebble, and then it is ready to receive the painting.

The process of painting is illustrated in Plate IV, 1,2 , where the woman who really does the work, but who could not be photographed, is represented by a boy. The women exhibit very great proficiency. Working from memory and without any pattern before them, they paint an entire bowl in a few minutes, laying on the 
colour with a thin feather. The colouring is in monochrome, viz., a dark purple at Edfu, red at Tukh, black at Ballas, and is not sensibly altered in firing. In Plate V, the most frequent designs are illustrated. When they have been painted the pots are fired in one of the large kilns to be described in the next section, which are used for all the classes of pottery made at these three places. Though the painted patterns are not affected by the fire, yet, whether owing to a difference in the composition of the body or to a variation in the intensity of the heat, the slip which remains as a white field in the Tukh and Ballas ware is changed by the fire to a bright orange in the Edfu specirnens. It may be remarked that the composition of the body is not identical at all three places, for, while at Edfu it consists merely of Nile mud and ashes, at Tukh and Ballas a fourth part of the same white clay that is used for the slip is added to these ingredients.

III. Household Pottery of the class illustrated in Plate VI is made at very many places. Certain towns, however, have acquired a special reputation for the excellence of their products, which they export all over Egypt. Thus the large water-pitchers which are in general use throughout the country are almost all made at Ballas, and derive their name from that village. And again, the finest of the porous water-bottles (Plate VI, 1, 13-17), are manufactured at Keneh, which does a' considerable export trade.

All this household pottery without exception is made on a wheel, the construction of which may be best understood from the illustration in Plate IV, 3. The potter is seated on a board, and impels the large wooden fly-wheel with his foot, thus rotating the wooden table upon which the pot is to be fashioned; the table is brought up to a convenient height for the hand by building up with mud. In the example illustrated the fly-wheel was about 4 feet and the table about 1 foot in diameter, but the latter, being only 3 inches deep, did not reach by about 12 inches to a convenient height for work. A block of dried mud about 6 inches high had therefore been placed upon it, and another block of wet mud upon this. The wet mud formed the bed for a platter of dry mud upon which the pot was now to be formed.

Taking a lump of clay of such size as he judges will suffice for the pot which he contemplates making, the potter sets it on the platter and begins his creative work. With incredible swiftness the soft lump takes shape, and almost quicker than the eye can note passes through a protean succession of changing forms until in two or three minutes it emerges as a graceful water-bottle (Plate VI, 1.)

A plate or bowl in its earlier stages gives little hint of its final form; the clay as first set on the platter is a solid cylinder, against the outside of which the potter presses his two hands, and instantly the surface is ploughed into wide furrows where his fingers have rested. He moves his hands upwards, and the furrows become spiral; then suddenly he presses his thumb downwards into the centre of the mass and a wide hollow opens out. This is the cuncavity of the rudimentary bowl. Next he holds one hand against the outside surface and with the other presses against the inside, rapidly fashioning and smoothing all the while, until he has 
produced a bowl like that which forms the main part of the grinder shown in Plate VI, 4 (to which VI, 5 also belongs), or a plate such as is figured in Plate VI, 2.

For a jug (Plate VI, 3,) or other handled pot a second stage is necessary. The vessel itself is first formed, then it is left to dry and the handle and spout are only added later with separate pieces of clay. Otherwise all pots, unless they are of large dimensions, are usually made at one sitting and from a single lump of clay, though bowls, which are apt to work too thin at the point where they stand on the wheel, are strengthened with a small extra piece which is bedded at the last moment into the centre of the interior.

The larger pots, however, are made in more than one piece. This is the case, for instance, with the $z \hat{\imath} r$, or water-pitcher (Plate VI, 8, 9, 12), the Ballas, and some of the gawadys. Two kinds of gawadys, which are the familiar jars used for the water-wheel, are here illustrated. One (Plate VI, 10), was made in a single piece, the other (Plate VI, 6), which is shown just as it came from the wheel, was made in two pieces, that is to say, the part round which the string is coiled was formed first and was placed mouth downwards for the other half to be added to it.

It will be observed that several of the specimens illustrated in Plate VI have string coiled round them. This is the method adopted for impressing a very simple and familiar ornamentation. If a $z \hat{\imath} r$, which is one of the larger pots (Plate VI, Figs. 8, 9, 12), is being made, it will have attained about half its future height as it stands on the wheel, when a long piece of twisted string is taken and coiled round it; then the next piece is built on to the bottom half with a second instalment of clay, the place of the join being neatly smoothed with a potsherd. Yet another thick roll of clay is taken on to build the last section before the rim, and the rim itself is made with a fourth instalment. The smoothing of the surface is always done with a sherd while the pot is on the wheel, and the nicking of the rim in plates or bowls (Plate II, Fig. 2) is effected with the finger or with a piece of tin. All the ornamentation is produced by the simplest means. To take the $z \hat{\imath} r$ again as an example, the patterns as well as the dimensions ${ }^{1}$ vary, but the impression of the string is almost always found on the lower half. Above this, in the Edfu specimens, a concentric band of pittings is made with the forefinger at about a third of the distance from the top, and above and below this band, again, vertical or diagonal lines are incised in sets of three by means of three thin straws held together in the hand. At 'Iukh the pattern is slightly different, but is produced by the same means.

The pots, then, have now been shaped and ornamented. They are removed from the wheel, and, still adhering to the platters on which they were made, are left in the sun to dry. In Plate VI, Figs. 1-13, they are shown. at this stage, the clay still wet and the strings in place. After about five days' drying in the open air-the time of course must vary with the season-they are ready to be fired

1 These water-pitchers have been made large enough to hold a man. A pasha, whose fame yet lives, used to administer justice in the hot weather seated in a $z \hat{\imath} r$ with a negro slave pouring water over his head. 
The kiln is of much of the same type everywhere; that of the Edfu pottery establishment was four-sided, and measured about 9 feet in diameter and 10 feet in depth. Three feet from the bottom was an arrangement of bars of brick, five bars one way and two the other, below which the fuel was inserted through a low door in the side of the kiln. Rubbish of all kinds, straw, charcoal or anything else, is used indiscriminately for the fire, which is left burning some four hours. The pots are placed on the bars and on the spaces between the bars, and burn to a reddish colour or to a powdery white according to the nature of the clay. This of course varies in different places; the composition of the body at Edfu, Tukh, and Ballas has been given above. Another potter at Tukh, whose work I have not described, since he made only two or three varieties of household pots and none of the decorated, used a different body, viz., one-third Nile mud and a little ash blended with two-thirds of a white earth brought from Kossir. His household pots were, moreover, coated with a slight wash of the same white earth and burned to a yellowish-red. I have stated that household pottery is seldom covered with any kind of slip, and this is true of all but a very few varieties. The whiteness of such water pots as the Gullal in Plate VI, Figs. 14, 18, is simply due to the superior character of the clay. These five specimens were made at Keneh itself, and, unlike those figured in Plate VI, 1, 13, had been dried and fired before they were photographed. The Keneh clay is obtained from a plot in the cultivation area not far from the railway station; it is not mixed with Nile mud, but only with about a fourth part of ashes from the fire. The process of manufacture at Keneh does not differ from that which has just been described; the pots are made in one piece, except when there is a perforated sheet on the inside for filtering the liquid. Then they are made in two pieces, viz., the first up to the filtering holes, which are pierced with a pointed stick in the wet clay, and the second piece above these holes.

I reserve for a future occasion some remarks upon the interesting parallels which some of these modern pottery fabrics present with ancient Egyptian pottery of various periods.

\section{Description of Plates.}

Plate I. Specimens of the hæmatitic wares of Upper Egypt.

Fig. 1, from Shammah.

Fig. 2, from Umm-Barakat.

Figs. 3-13, from Assuân.

Plate II. Fig. 1. The women of a family making pottery, Shammah.

Fig. 2. The potter-woman laying on the hæmatitic slip, Umm-Barakat.

Plate III. Fig. 1. The open air furnace, showing firing of pottery, Assuân.

Fig. 2. The open air furnace, showing pottery when the firing is just completed, Assuân.

Fig. 3. The potter's establishment at Edfu.

Plate IV. Figs. 1 and 2. Boy (who represents a woman) painting the pattern with a feather.

Fig. 3. The potter at work with his wheel, Tukh. 


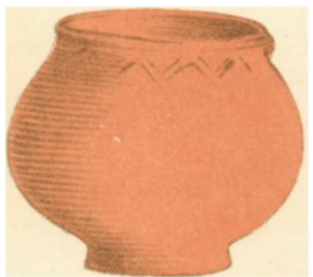

1

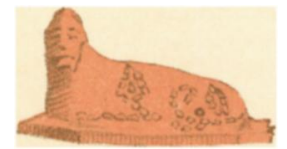

4

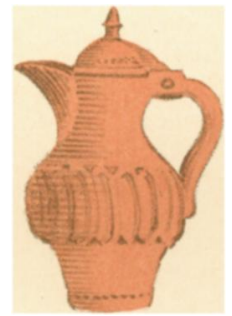

8

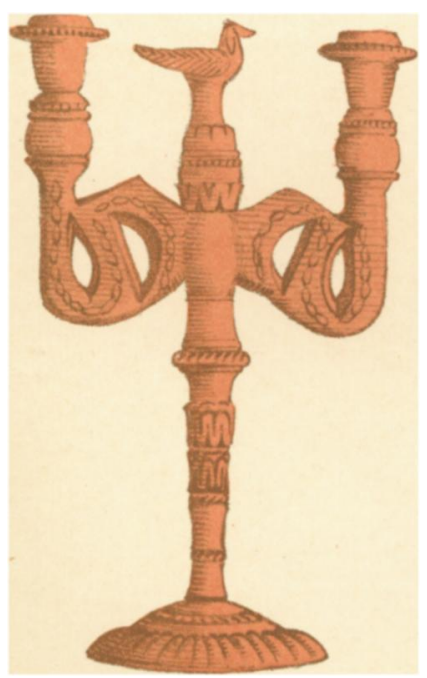

11

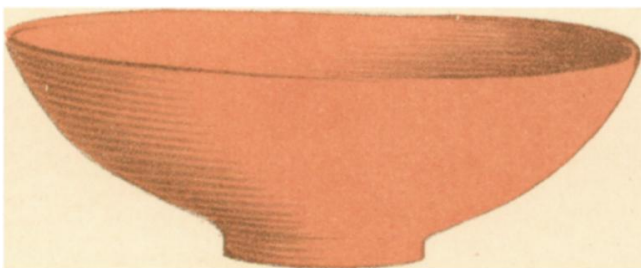

2
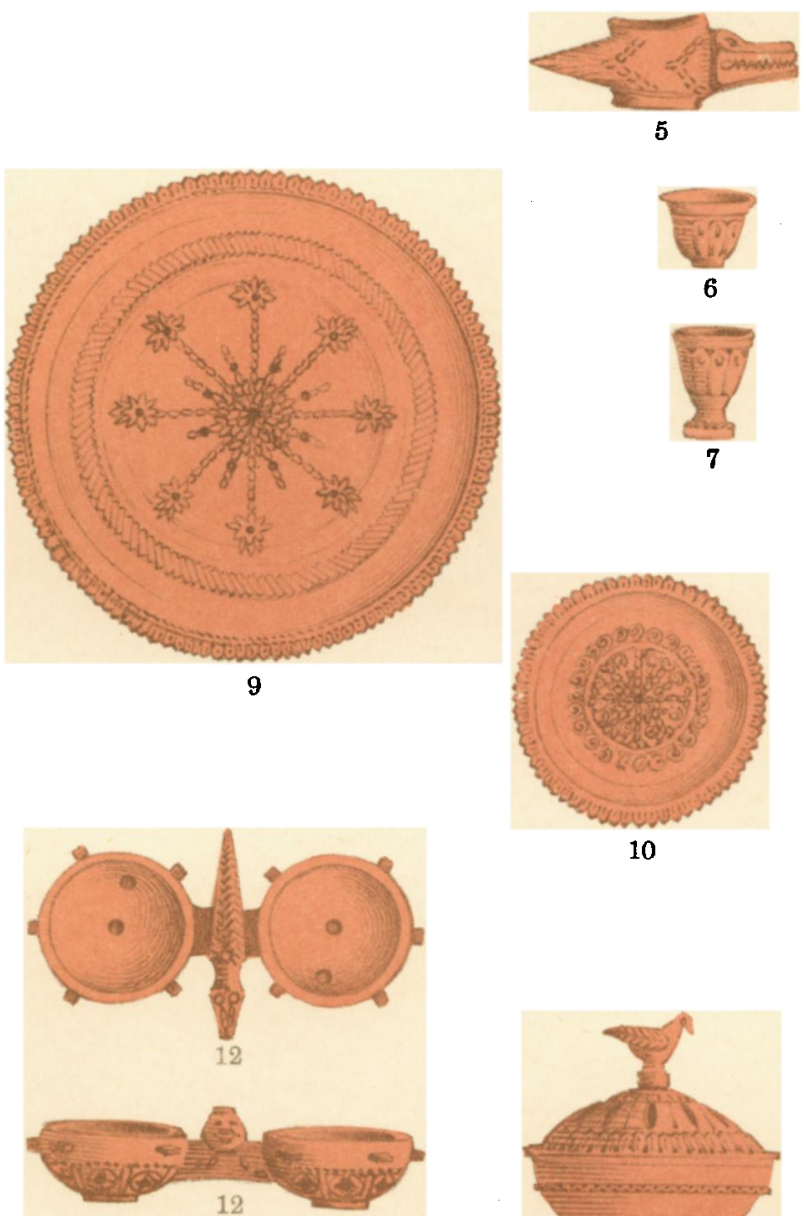

10

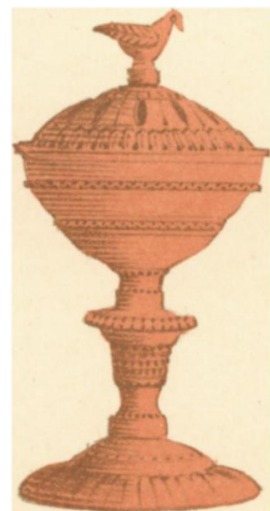

13

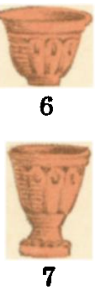

3

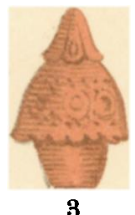

7

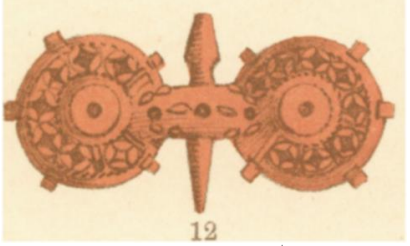

Bale \& Danieloson, Ltid, L.ith.

THE MANUFACTURE OF POTTERY IN UPPER EGYPT. 


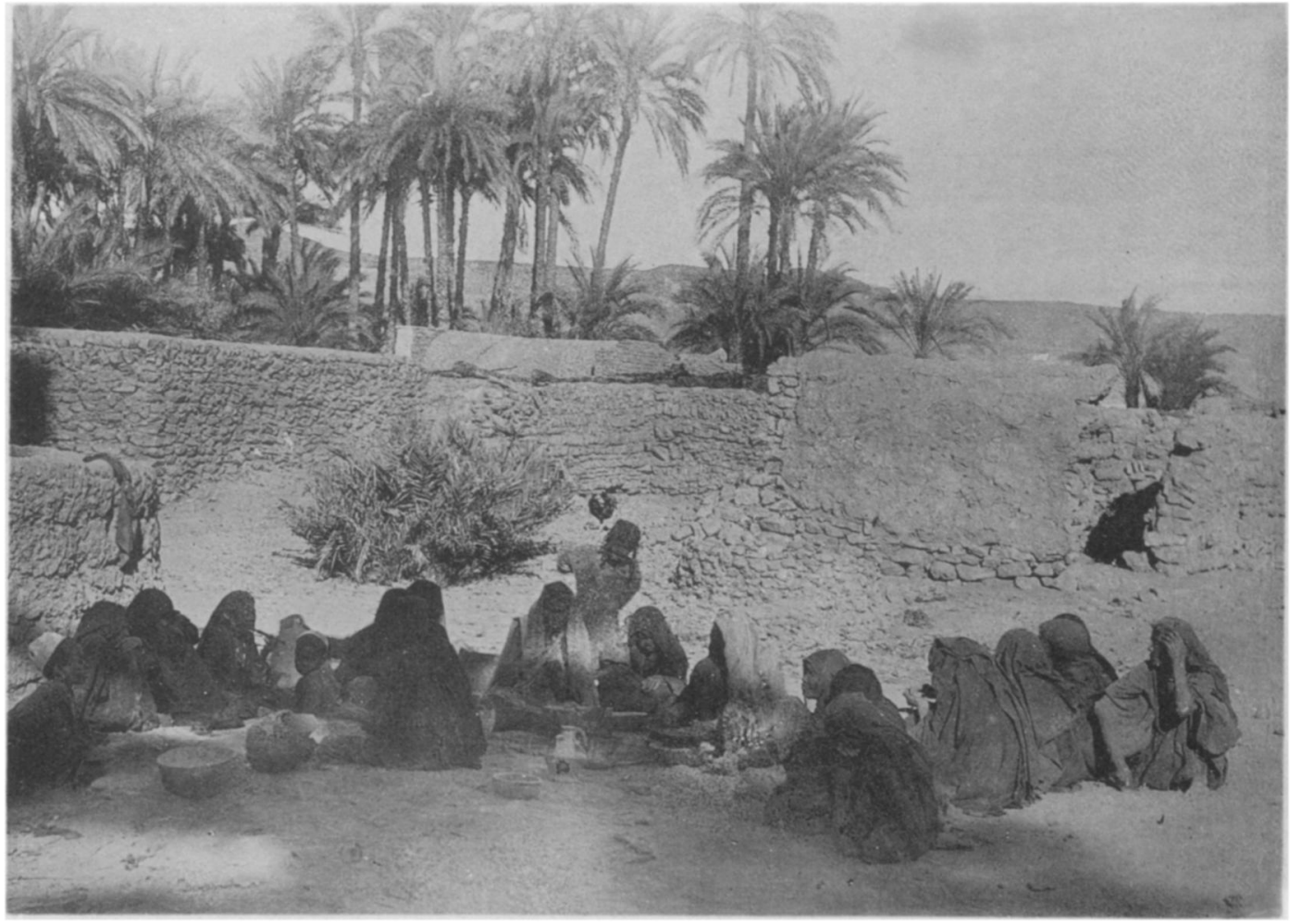

FIG. I

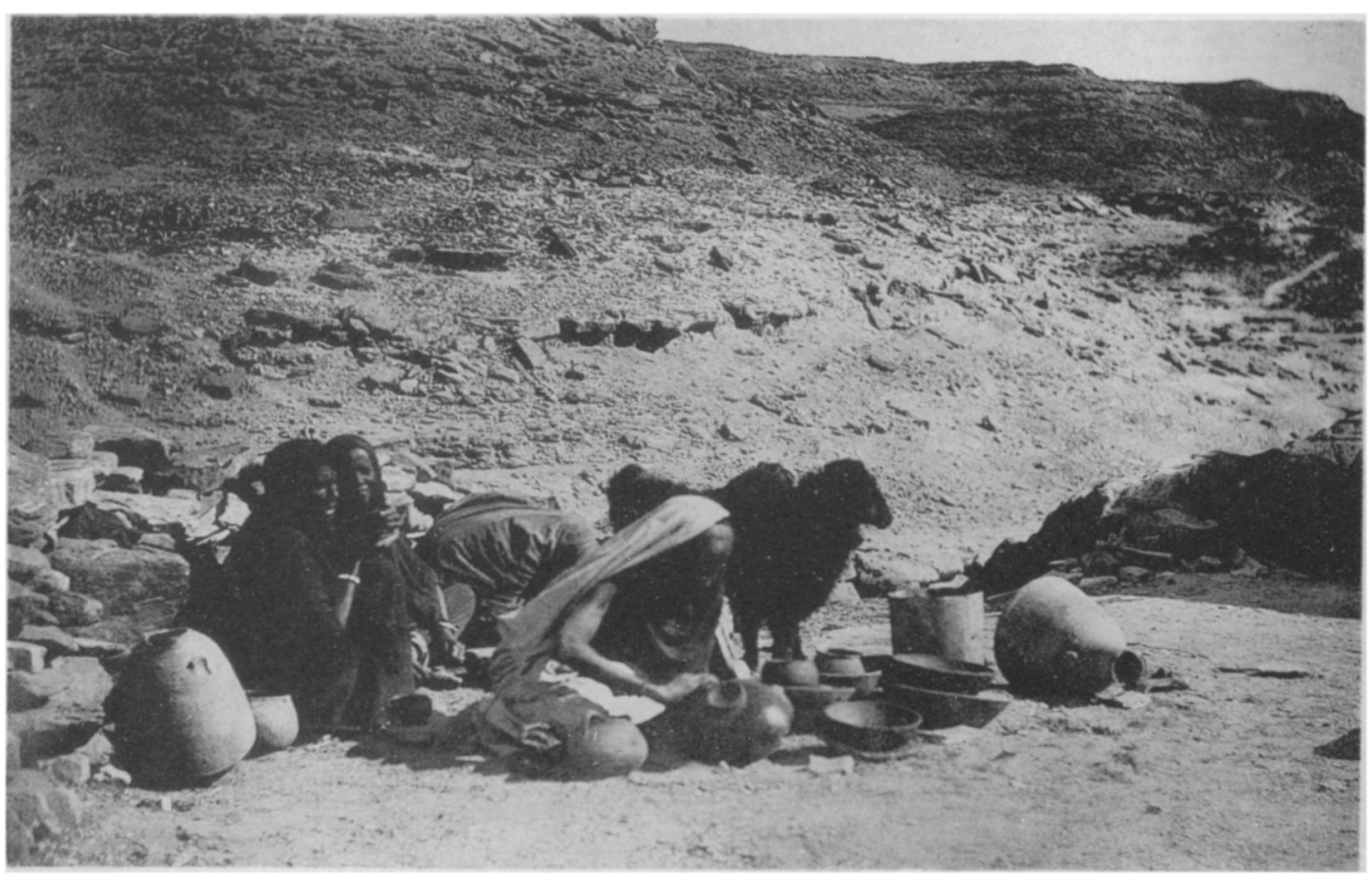

Fia. 2.

THE MANUFACTURE OF POTTERY IN UPPER EGYPT. 


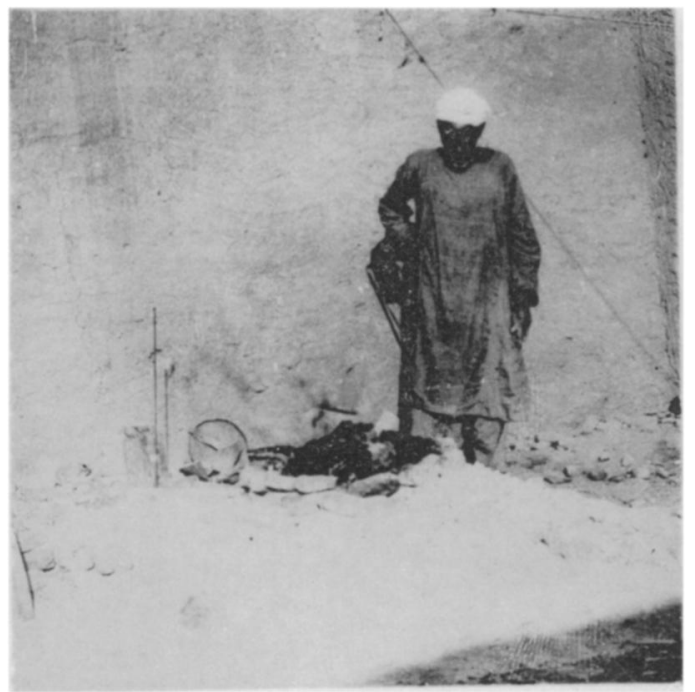

Fig. 1.

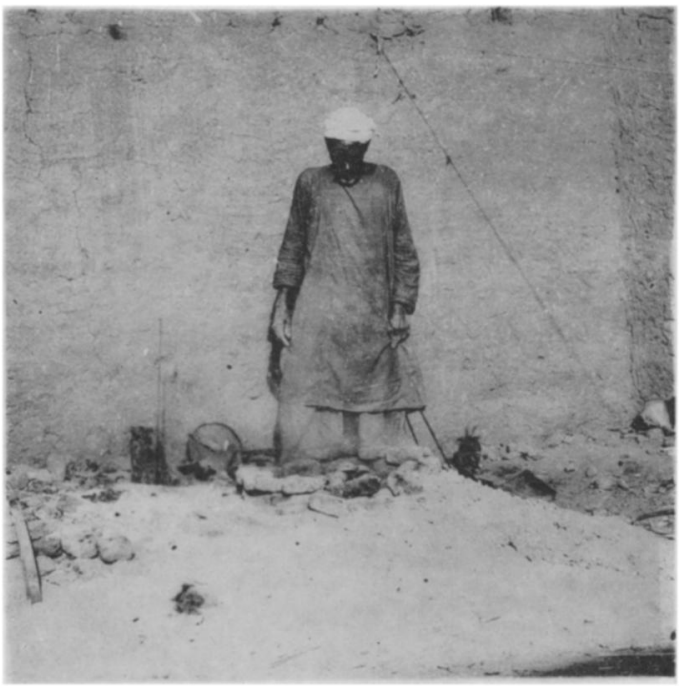

Fia. 2.

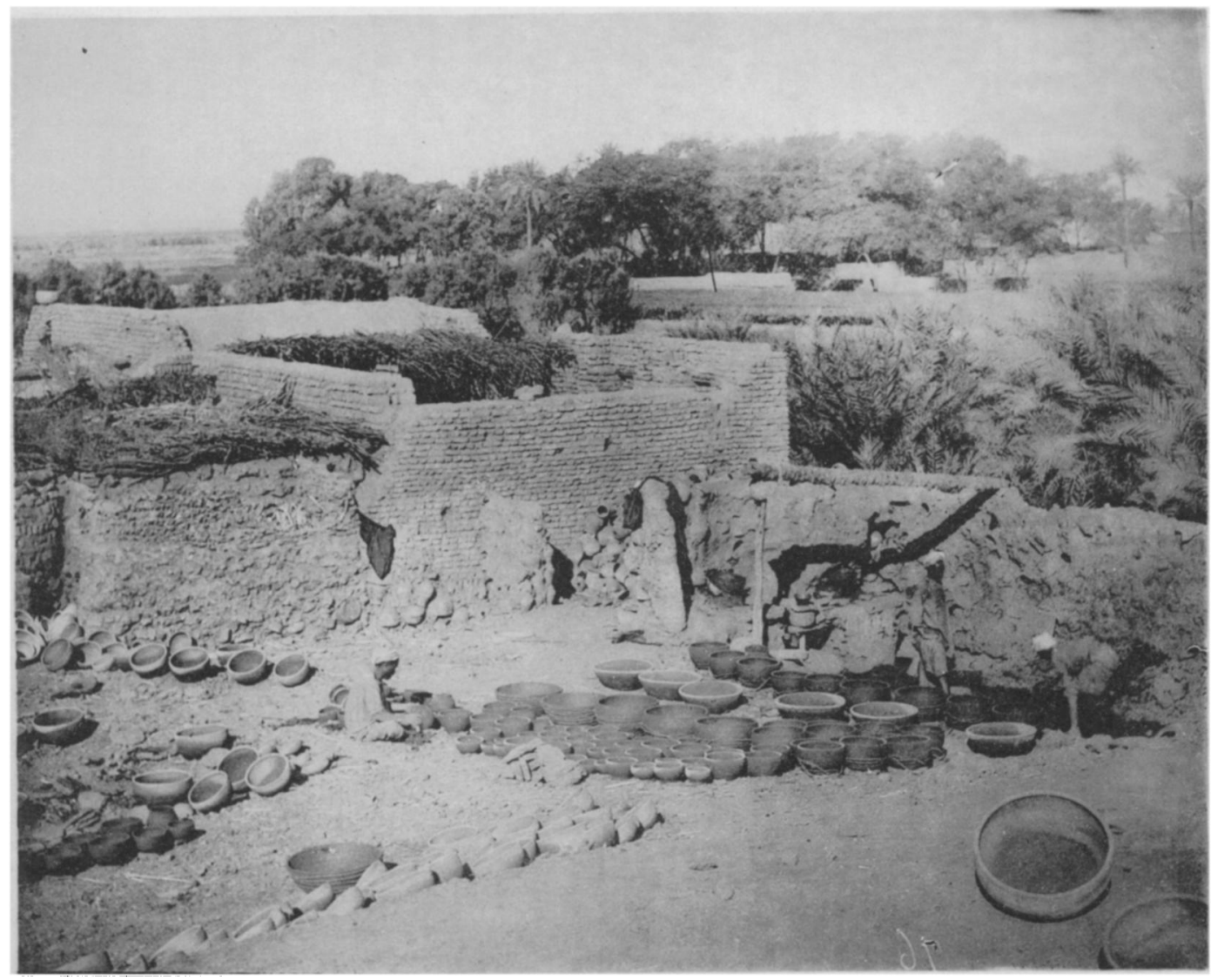

F1a. 3.

THE MANUFACTURE OF POTTEPY IN UPPER EGYPT. 


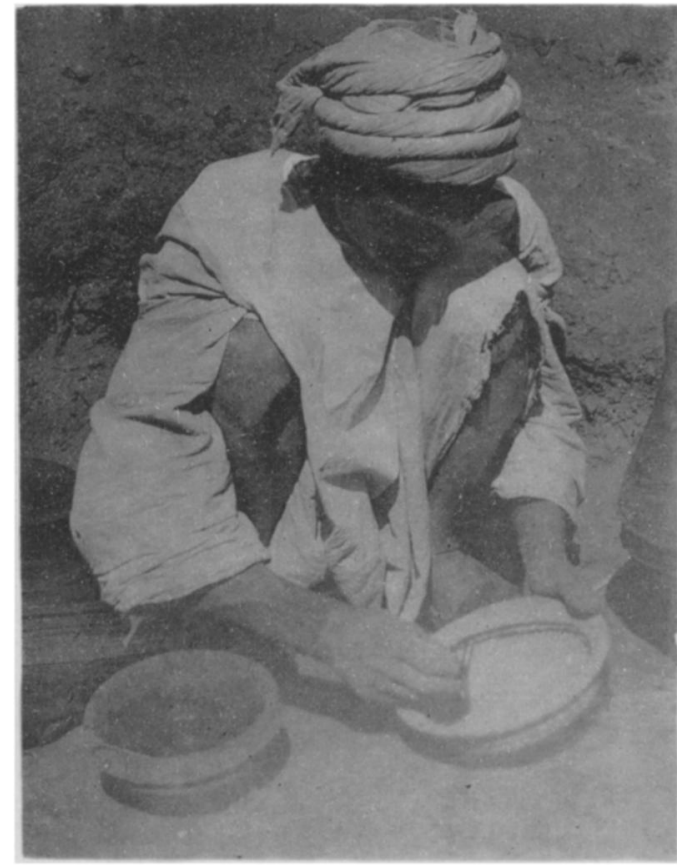

Fig. 1.

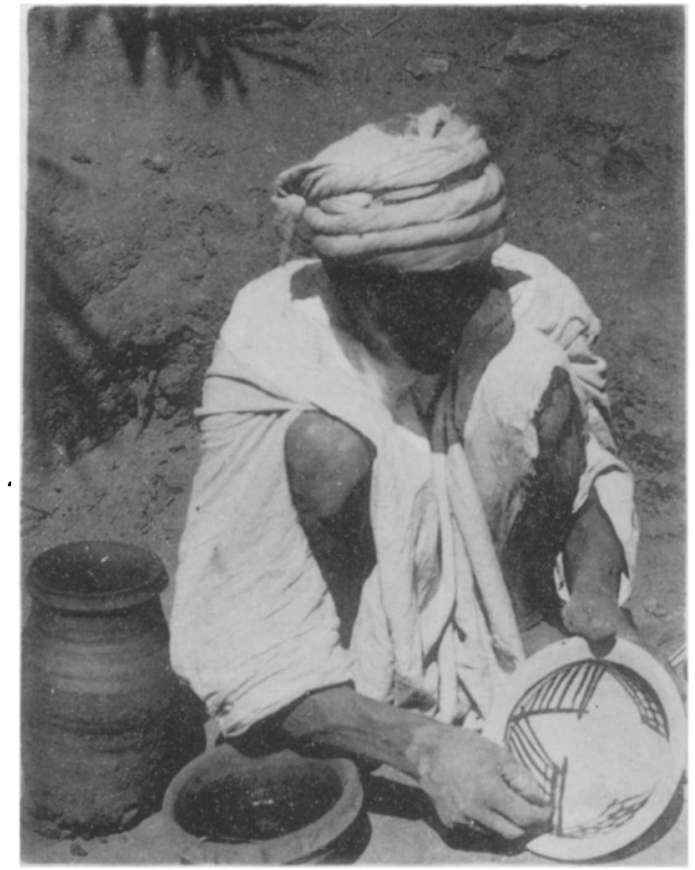

FIG. 2.

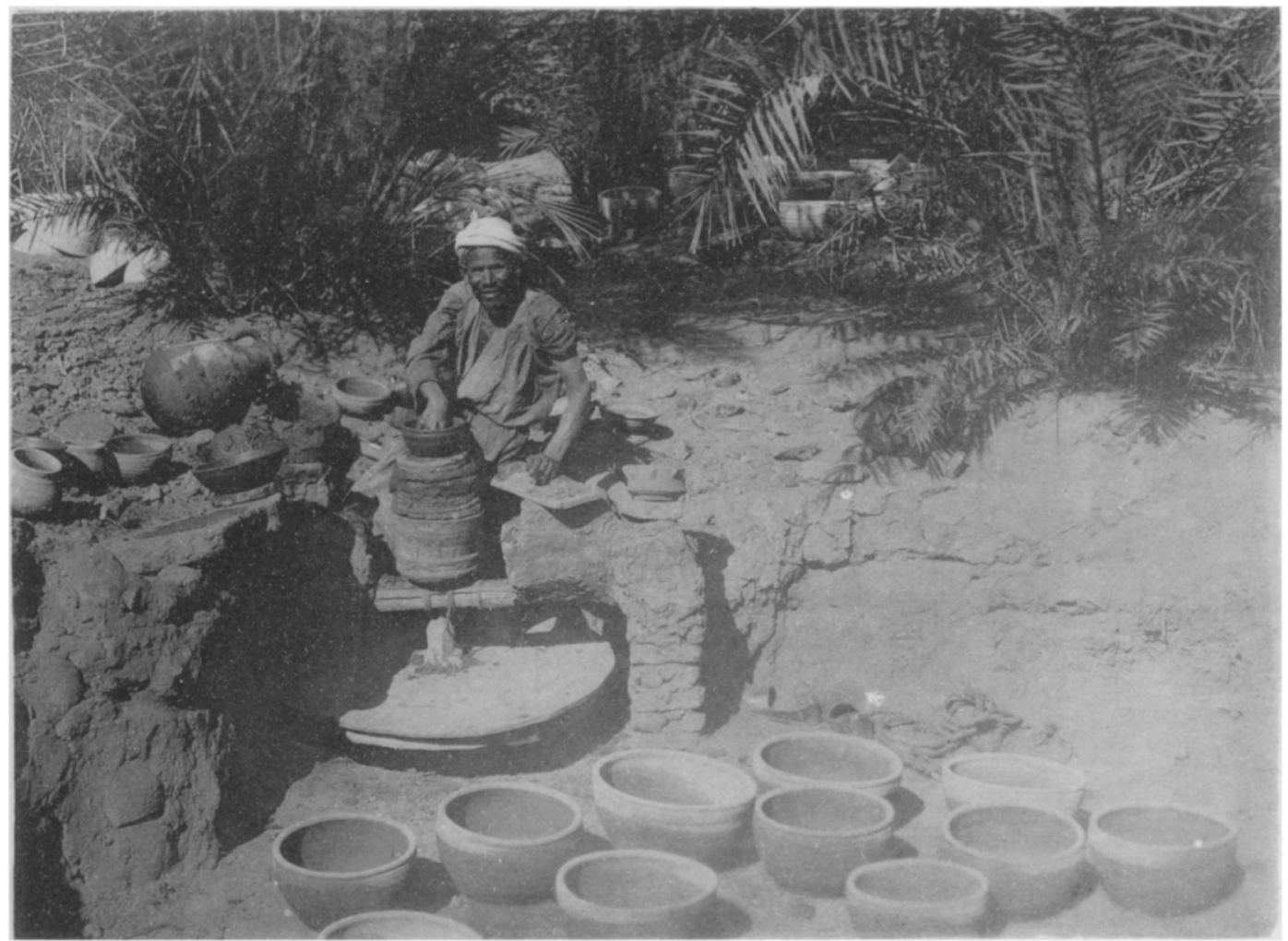

Fig. :3.

THE MANUFACTURE OF POTTERY IN UPPER EGYPT. 

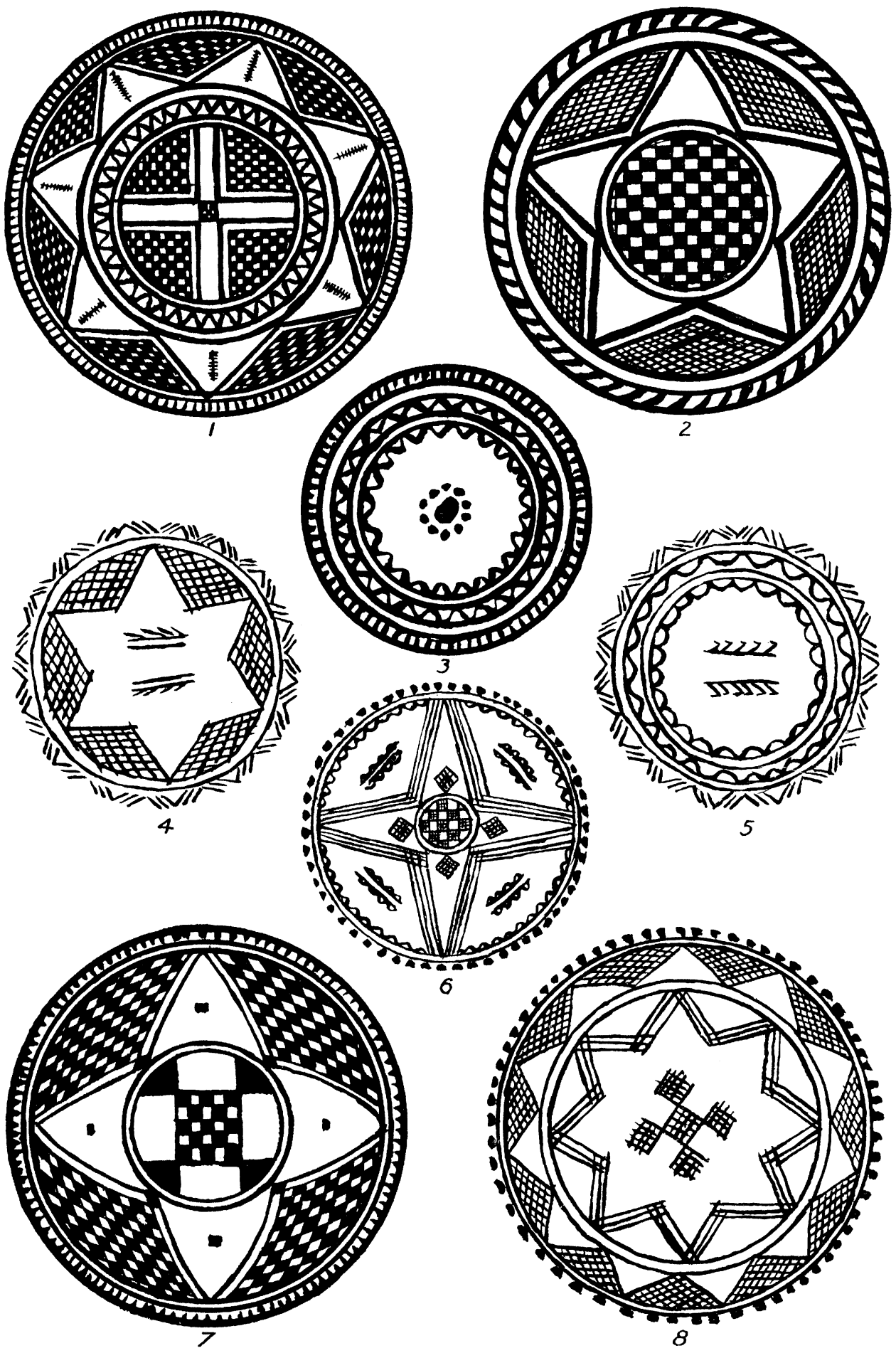

THE MANUFACTURE OF POTTERY IN UPPER EGYP'T. 
Journal of the Anthropological Institute, Vol. XXXV, 1905, Plate VI.
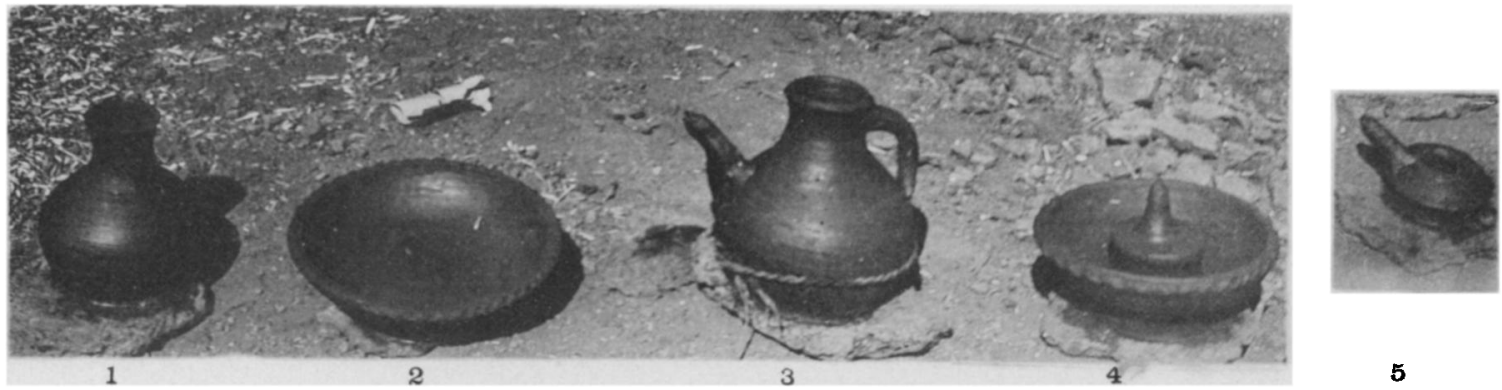

5
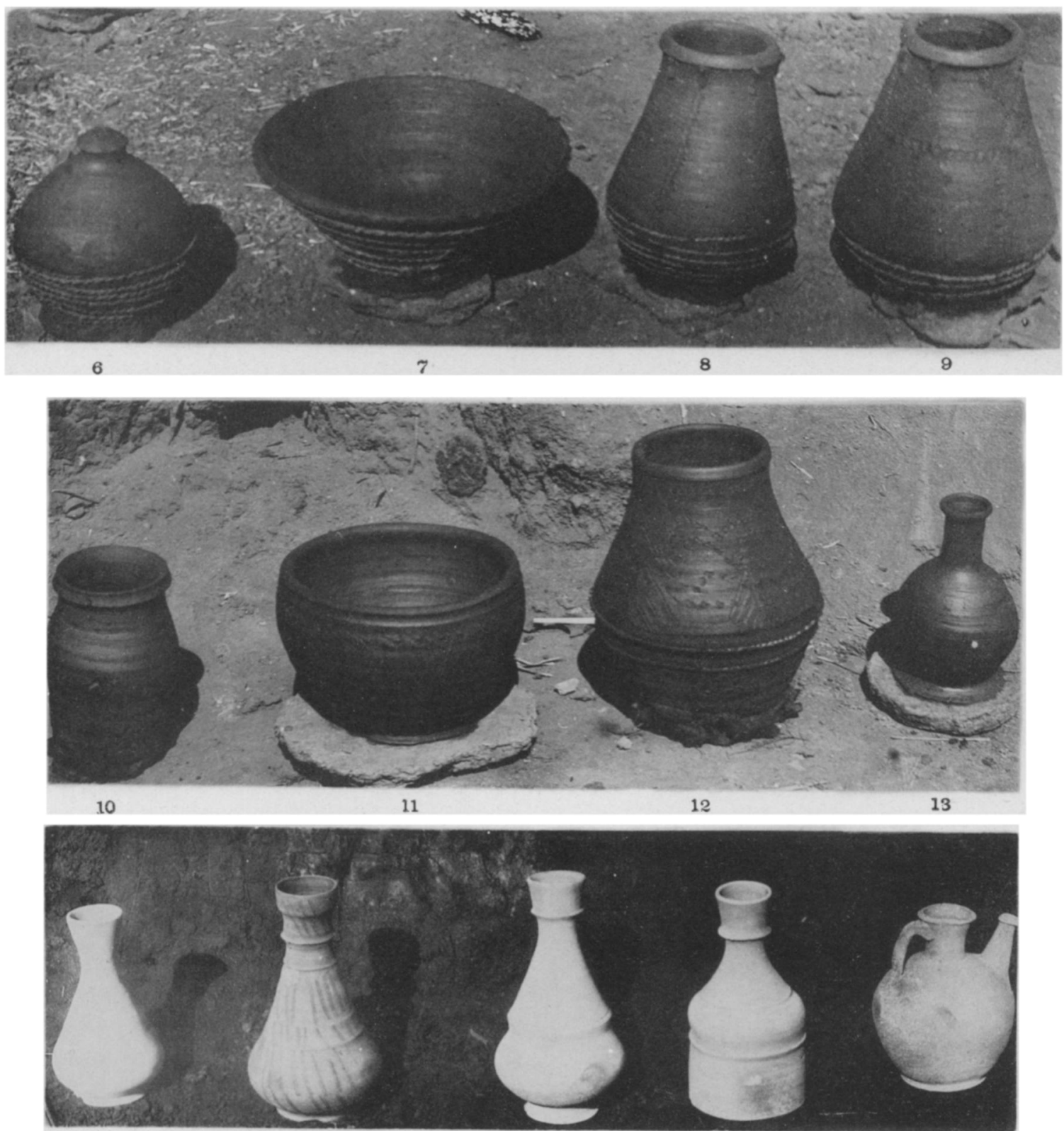

13

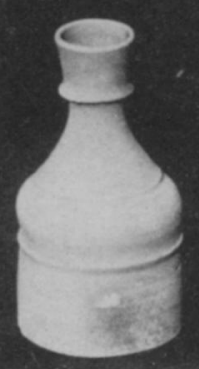

17

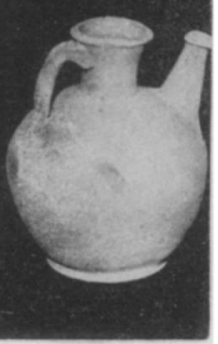

18

THE MANUFACTURE OF POTTERY IN UPPER EGYPT. 
Plate V. The chief patterns which occur on the painted wares.

Figs. 1, 2, 3 and 7 from Edfu.

Figs. 4 and 5 from Tukh.

Figs. 6 and 8 from Ballas.

Pláte VI. Household pottery.

Figs. 1-9 from Edfu.

Figs. 10-13 from Tukh.

Figs. 14-18 from Keneh. 